\title{
Oxidized and Aggregated Recombinant Human Interferon Beta is Immunogenic in Human Interferon Beta Transgenic Mice
}

\author{
Miranda M. C. van Beers $•$ Melody Sauerborn $•$ Francesca Gilli $•$ Vera Brinks $•$ Huub Schellekens $•$ Wim Jiskoot
}

Received: 17 November 2010 / Accepted: 8 April 2011 / Published online: 5 May 2011

(C) The Author(s) 2011. This article is published with open access at Springerlink.com

\begin{abstract}
Purpose To study the effect of oxidation on the structure of recombinant human interferon beta-la (rhIFN $\beta-1 a)$ and its immunogenicity in wild-type and immune-tolerant transgenic mice. Methods Untreated rhIFN $\beta$ - Ia was degraded by metalcatalyzed oxidation, $\mathrm{H}_{2} \mathrm{O}_{2}$-mediated oxidation, and guanidinemediated unfolding/refolding. Four rhIFN $\beta$-la preparations with different levels of oxidation and aggregation were injected intraperitoneally in mice $15 \times$ during 3 weeks. Both binding and neutralizing antibodies were measured.
\end{abstract}

Results All rhIFN $\beta-1$ a preparations contained substantial amounts of aggregates. Metal-catalyzed oxidized rhIFN $\beta-$ la contained high levels of covalent aggregates as compared with untreated rhIFN $\beta$-la. $\mathrm{H}_{2} \mathrm{O}_{2}$-treated rhlFN $\beta$-la showed an increase in oligomer and unrecovered protein content by HPSEC; RP-HPLC revealed protein oxidation. Guanidine-treated rhIFN $\beta$ - I a mostly consisted of dimers and oligomers and some non-covalent aggregates smaller in size than those in untreated rhIFN $\beta$ - Ia. All degraded samples showed alterations in tertiary protein structure. Wild-type mice showed equally high antibody responses against all preparations. Transgenic mice were discriminative, showing elevated antibody responses against both metal-catalyzed oxidized and $\mathrm{H}_{2} \mathrm{O}_{2}$ - treated rhIFN $\beta$ - Ia as compared to untreated and guanidinetreated rhIFN $\beta$ - Ia.

Conclusions Oxidation-mediated aggregation increased the immunogenicity of rhIFN $\beta-1 \mathrm{a}$ in transgenic mice, whereas aggregated preparations devoid of measurable oxidation levels were hardly immunogenic.

KEY WORDS antibodies immunogenicity - oxidation . protein aggregates $\cdot$ recombinant human interferon beta

\begin{tabular}{|c|c|}
\hline \\
\hline \multicolumn{2}{|c|}{ BABs binding an } \\
\hline hIFN $\beta$ & human interferon beta \\
\hline i.p. & intraperitoneally \\
\hline $\lg G$ & immunoglobulin G \\
\hline$M \times A$ & myxovirus resistance protein $\mathrm{A}$ \\
\hline NABs & neutralizing antibodies \\
\hline rhIFNa-2b & recombinant human interferon alpha- $2 b$ \\
\hline IFN $\beta$ & recombinant human interferon beta \\
\hline IFN $\beta-$ - a & recombinant human interferon beta- $\mid \mathrm{a}$ \\
\hline rhIFN $\beta-I b$ & recombinant human interferon beta- $\mathrm{l} b$ \\
\hline SDS & sodium dodecyl sulfate \\
\hline $\mathrm{TRU} / \mathrm{ml}$ & ten-fold reduction units per $\mathrm{ml}$ \\
\hline
\end{tabular}

M. M. C. van Beers • W. Jiskoot $(\square)$

Division of Drug Delivery Technology, Leiden/Amsterdam Center

for Drug Research (LACDR), Leiden University

Einsteinweg 55, 2333 CC, Leiden, The Netherlands

e-mail:w.jiskoot@lacdr.leidenuniv.nl

M. M. C. van Beers • M. Sauerborn • V. Brinks • H. Schellekens Department of Pharmaceutics, Utrecht Institute for Pharmaceutical Sciences (UIPS), Utrecht University

Utrecht, The Netherlands
F. Gilli

Clinical Neurobiology Unit, Neuroscience Institute Cavalieri Ottolenghi (NICO), University Hospital San Luigi Gonzaga Orbassano, TO, Italy 


\section{INTRODUCTION}

Patients treated with therapeutic proteins frequently suffer from side effects or ineffective treatment caused by adverse immune responses against the drug (1). Multiple sclerosis patients treated with recombinant human interferon beta $($ rhIFN $\beta)$ may experience reduced efficacy of the drug during chronic treatment (2). The therapeutic effect of $\operatorname{rhIFN} \beta$ is influenced by the formation of binding antibodies $(\mathrm{BABs})$ and neutralizing antibodies (NABs). High levels of $\mathrm{NABs}$, often preceded by BABs, block the biological activity of the protein. Molecular characteristics have been found to play a key role in the unwanted immunogenicity of protein pharmaceuticals $(3,4)$.

Endogenous human interferon beta (hIFN $\beta$ ) is a cytokine produced by macrophages and epithelial and fibroblast cells. The protein binds to the cell receptor as a dimer and has antiviral, antiproliferative and immunomodulatory properties (5). Recombinant human interferon beta-la (rhIFN $\beta-1 \mathrm{a})$ is produced in CHO cells, and its primary sequence is identical to that of natural hIFN $\beta$. The therapeutic protein has a molecular weight of approximately $22.5 \mathrm{kDa}$, including 166 amino acids and a single $\mathrm{N}$ linked carbohydrate chain. The protein structure comprises five $\alpha$-helices, one intramolecular disulfide bond, and a free cysteine near the N-terminus that might play a role in the formation of protein aggregates through inter- and intramolecular disulfide scrambling $(6,7)$. The carbohydrate chain was suggested to protect an unusually large hydrophobic region of the protein, as de-glycosylation of rhIFN $\beta$ la renders the protein poorly soluble and prone to aggregation (8).

The presence of aggregates not only affects the biological activity of rhIFN $\beta$ but can also enhance its immunogenicity (9). This is illustrated by the relatively low bioactivity and high clinical immunogenicity of the commercial product Betaferon ${ }^{\circledR}$. The active substance of Betaferon ${ }^{\circledR}$ is rhIFN $\beta$ $1 \mathrm{~b}$, a non-glycosylated form of rhIFN $\beta$ that is produced in E. coli and forms up to $60 \%$ large, soluble and non-covalent aggregates (8). Large, non-covalent aggregates were also detected in solutions of glycosylated rhIFN $\beta$-1a in a buffer of sodium phosphate and sodium chloride at pH 7.2 (10). Removing the aggregates and formulating the protein in a sodium acetate buffer at $\mathrm{pH} 4.8$ with polysorbate 20 and arginine significantly reduced the immunogenicity of the protein in transgenic mice immune tolerant for human interferon beta. Incubation of $\operatorname{rhIFN} \beta$-1a at low $\mathrm{pH}$ and high salt induced the formation of covalent aggregates, but did not enhance its immunogenicity (10). So far, studies with transgenic immune-tolerant mice have shown that aggregates potentially increase the immunogenicity of rhIFN $\beta$; however, not all aggregates are equally immunogenic (10-12).
The immunogenicity of a therapeutic protein can also be enhanced by chemical modification, such as hydrolysis, deamidation, or oxidation (13). Oxidation is one of the major degradation pathways for proteins $(14,15)$. Those amino acids containing a sulfur atom (Cys and Met) or an aromatic ring (His, Trp, Tyr and Phe) are most susceptible and involved in numerous types of oxidative mechanisms (for an overview, see reference (16)). Oxidation of therapeutic proteins occurs during formulation, fill-finish, freeze-drying or storage, for example, due to exposure to intense light, trace amounts of metal ions or peroxide impurities in, e.g., polysorbate excipients $(14,15,17)$. Lam et al. described the oxidation of a recombinant humanized monoclonal antibody in liquid formulations when exposed to intense light and elevated temperatures $\left(30^{\circ} \mathrm{C}\right.$ and $\left.40^{\circ} \mathrm{C}\right)(17)$. Also, corrosion of stainless steel containers by chloride ions in the formulation buffer at low $\mathrm{pH}$ can generate iron ions that catalyze methionine oxidation (17).

Oxidation of biological proteins can have various consequences, such as inhibition of enzymatic and binding activities, increased or decreased uptake by cells, increased susceptibility to proteolysis and aggregation, and altered immunogenicity (16). UV light at $302 \mathrm{~nm}$ induced oxidation of Trp residues and subsequent aggregation of the model therapeutic protein type I soluble tumor necrosis factor receptor (18). Peroxodisulfate-mediated oxidation of recombinant human interleukin-2 induced a change in the secondary structure of the protein, as observed by far-UV circular dichroism (W. Jiskoot, unpublished results). Metalcatalyzed oxidation of human relaxin resulted in alterations in secondary and tertiary structure and increased exposure of hydrophobic surface, leading to aggregation and precipitation (19). Hermeling et al. demonstrated the formation of highly immunogenic aggregates upon oxidation of recombinant human interferon alpha-2b (rhIFNo$2 \mathrm{~b}$ ) via catalysis with copper ions (20). A combination of ascorbic acid and transition metal ions $\left(\mathrm{Fe}^{3+}\right.$ or $\left.\mathrm{Cu}^{2+}\right)$ is often used as a model system to study the effect of sitespecific metal-catalyzed oxidation. The metal ions bind to specific chelating or ionic spots of the protein, forming active oxygen intermediates such as $\mathrm{H}_{2} \mathrm{O}_{2}, \mathrm{O}_{2}$ ' and $\mathrm{HO}$, which subsequently react with one of the amino acid side chains in their immediate proximity (16). Protein damage can also occur more distant from the initial oxidation event, e.g., when oxidized Cys residues catalyze the oxidation of other amino acids (21).

Here, we present data on the effect of two different oxidation pathways on the structure and aggregation state of rhIFN $\beta$ - $1 \mathrm{a}$ and its immunogenicity in wild-type and transgenic immune-tolerant mice. For comparison, two rhIFN $\beta$-la preparations containing aggregates but no measurable amounts of oxidation products were also tested. The results strongly suggest that the combination of oxidation and 
aggregation increases the risk of antibody responses against $\operatorname{rhIFN} \beta-1 \mathrm{a}$.

\section{MATERIALS AND METHODS}

\section{RhIFN $\beta$ Products}

Recombinant hIFN $\beta$-la was supplied by Biogen Idec Inc. (Cambridge, MA, USA) as a $0.26 \mathrm{mg} / \mathrm{ml}$ solution in $20 \mathrm{mM}$ sodium acetate buffer and $154 \mathrm{mM}$ arginine at $\mathrm{pH}$ 4.8. Before use, this solution was dialyzed with a $3.5 \mathrm{kDa}$ MWCO Slide-A-Lyzer Cassette (Perbio Science, Etten-Leur, the Netherlands) against $100 \mathrm{mM}$ sodium phosphate buffer and $200 \mathrm{mM}$ sodium chloride at pH 7.2 (PBS). This solution is further referred to as untreated rhIFN $\beta$-la.

Three different degradation products were prepared from untreated rhIFN $\beta$-1a. To obtain metal-catalyzed oxidized rhIFN $\beta$-1a, untreated $\operatorname{rhIFN} \beta$-1a, diluted to $200 \mu \mathrm{g} / \mathrm{ml}$ with PBS, was incubated with $4 \mathrm{mM}$ ascorbic acid and $0.04 \mathrm{mM} \mathrm{CuCl}_{2}$ for $3 \mathrm{~h}$ at room temperature according to $\mathrm{Li}$ et al. (19). The oxidation reaction was stopped by adding $100 \mathrm{mM}$ EDTA to a final concentration of $1 \mathrm{mM}$. Hydrogen peroxide $\left(\mathrm{H}_{2} \mathrm{O}_{2}\right)$-mediated oxidation was achieved by incubation of $200 \mu \mathrm{g} / \mathrm{ml}$ untreated rhIFN $\beta$-la with $0.005 \%(v / v) \quad \mathrm{H}_{2} \mathrm{O}_{2}$ for $20 \mathrm{~h}$ at $37^{\circ} \mathrm{C}$ according to the European Pharmacopeia (22). The reaction was stopped by the addition of $12 \mathrm{mg}$ methionine per $\mathrm{ml}$ followed by incubation at room temperature for $1 \mathrm{~h}$. Finally, rhIFN $\beta$-la was unfolded by overnight dialysis of $200 \mu \mathrm{g} / \mathrm{ml}$ untreated rhIFN $\beta$-la against $6 \mathrm{M}$ guanidine hydrochloride at $4^{\circ} \mathrm{C}$. After degradation, the oxidized and guanidine-treated samples were dialyzed extensively against PBS. All rhIFN $\beta$-1a samples were stored at $-80^{\circ} \mathrm{C}$.

\section{Physicochemical Characterization}

\section{Visual Inspection}

RhIFN $\beta$-1a samples $(100 \mu \mathrm{g} / \mathrm{ml})$ were inspected visually at the lab bench with the sample buffer as a reference.

\section{Dynamic Light Scattering (DLS)}

The average diameter (Z-ave) of particles in $\operatorname{rhIFN} \beta-1 \mathrm{a}$ samples and their polydispersity index (PDI) were assessed with dynamic light scattering (DLS). Samples were diluted with the sample buffer to a concentration of $100 \mu \mathrm{g} / \mathrm{ml}$ protein and analyzed using a Malvern Zetasizer Nano ZS apparatus equipped with a red laser $(\lambda=633 \mathrm{~nm})$, a detector at $173^{\circ}$, and Dispersion Technology Software version 4.20. Samples were measured at $25^{\circ} \mathrm{C}$ in the presence or absence of $0.01 \%(w / v)$ sodium dodecyl sulfate (SDS).

\section{UV Spectroscopy}

UV absorbance was measured at $25^{\circ} \mathrm{C}$ in quartz cuvettes with a path length of $1 \mathrm{~cm}$ with an Agilent $8453 \mathrm{UV} / \mathrm{VIS}$ spectrophotometer and an Agilent 89090 A controller. Samples were diluted with the sample buffer to a concentration of $100 \mu \mathrm{g} / \mathrm{ml}$ rhIFN $\beta$ - $1 \mathrm{a}$ and measured in the presence or absence of $0.01 \%(w / v)$ SDS. Zero-order spectra were recorded at wavelengths of 190 to $1100 \mathrm{~nm}$. Second-derivative UV spectroscopy enabled us to monitor changes in the microenvironment of aromatic amino acid residues without interference of light scattering $(23,24)$. UV spectra $(\lambda=240-360 \mathrm{~nm})$ were recorded with an integration time of $15 \mathrm{~s}$ and a $1-\mathrm{nm}$ interval. Second-derivative spectra were calculated and interpolated with 99 data points using the Agilent UV-Visible ChemStation Software.

\section{High Performance Size Exclusion Chromatography (HP-SEC)}

RhIFN $\beta$-1a preparations $(100 \mu \mathrm{l}, 200 \mu \mathrm{g} / \mathrm{ml})$ were characterized with a TSKgel Super SW2000 column and Super SW guard column (Sigma Aldrich). A Shimadzu SPD-6AV UV detector recorded the chromatograms at a wavelength of $280 \mathrm{~nm}$. A flow rate of $0.35 \mathrm{ml} / \mathrm{min}$ was applied using a Waters 515 HPLC pump and 717 Plus autosampler. The mobile phase consisted of $200 \mathrm{mM}$ sodium chloride, $0.05 \%$ $(w / v)$ sodium azide and $0.1 \%(w / v)$ SDS in a buffer of $100 \mathrm{mM}$ sodium phosphate $(\mathrm{pH} 7.2)$, which was filtered through a $0.2-\mu \mathrm{m}$ filter prior to use.

\section{Reversed-Phase High Performance Liquid Chromatography (RP-HPLC)}

A Jupiter $300(5 \mu \mathrm{m}, 250 * 4.6 \mathrm{~mm}) \mathrm{C} 4$ column was used in combination with a SecurityGuard $(4 * 3 \mathrm{~mm}) \mathrm{C} 4$ guard column (Phenomenex, Amstelveen, the Netherlands). The mobile phase was delivered at a flow rate of $1 \mathrm{ml} / \mathrm{min}$ by a Waters 600 controller coupled to a Waters 717 Plus autosampler, and chromatograms were recorded with a UV detector (Waters 2487) at a wavelength of $214 \mathrm{~nm}$. The eluents were $10 \%$ acetonitrile with $0.1 \%$ trifluoroacetic acid (TFA) and 100\% acetonitrile with $0.1 \%$ TFA. After application of the sample $(20 \mu \mathrm{l}, 200 \mu \mathrm{g} / \mathrm{ml})$, an elution gradient was applied according to Geigert et al. (25).

\section{Immunogenicity Study}

\section{Mouse Breeding}

Human IFN $\beta$ transgenic immune-tolerant C57Bl/6 mice, previously developed by Hermeling et al. (11), were bred at the Central Laboratory Animal Institute (Utrecht University, the Netherlands). Transgenic mice were crossed with 
wild-type C57Bl/6 mice (Janvier, Bioservices, Uden, the Netherlands) to maintain the strain. Presence of the hIFN $\beta$ gene in the offspring was verified by PCR using chromosomal DNA obtained from ear tissue. Transgenic C57Bl/6 offspring were crossed with wild-type FVB/N mice (Janvier). Their C57Bl/6 x FVB/N hybrid offspring were genotyped, and both transgenic and non-transgenic littermates (12) were used in the animal experiment.

\section{Animal Experiment}

Food (Hope Farms, Woerden, the Netherlands) and water (acidified) were provided ad libitum, and the animal study was approved by the Institutional Ethical Committee. Blood was collected submandibularly from 40 wild-type and 40 transgenic mice before treatment was started $(11,12)$. Ten mice per group were injected intraperitoneally (i.p.) with $5 \mu \mathrm{g}$ of untreated, metal-catalyzed oxidized, $\mathrm{H}_{2} \mathrm{O}_{2}$-treated or guanidine-treated rhIFN $\beta$ - $1 \mathrm{a}$ at day $0-4$, day 7-11, and day 14-18. At days 7 and 14, blood was drawn submandibularly just before injection with rhIFN $\beta$ - la, and at day 21 all mice were sacrificed by bleeding through cardiac puncture under isoflurane anesthesia. Lithium heparin gel tubes were used to collect blood and obtain plasma samples by centrifugation (3000 g; $10 \mathrm{~min}$ ). Plasma was stored at $-80^{\circ} \mathrm{C}$ until analysis.

\section{Binding Antibody Assay}

The plasma samples were analyzed by direct ELISA according to the protocol described by Hermeling et al. (11). Plates were coated with untreated $\operatorname{rhIFN} \beta$-la to measure the levels of BABs that cross-react with the untreated protein. Absorbance values were measured at a wavelength of $405 \mathrm{~nm}$ and a reference wavelength of $490 \mathrm{~nm}$ using a BioTek EL808 microplate reader (Beun de Ronde, Abcoude, the Netherlands). The 100-fold diluted plasma samples were screened and defined positive if the background-corrected absorbance values were 10 times higher than that of the pre-treatment plasma. Titers of antihIFN $\beta$ IgG in positive plasma were determined by plotting the absorbance values of a serial dilution against $\log$ dilution. A standard anti-hIFN $\beta$ plasma with an average $\log$ titer value of $3.41 \pm 0.10(\mathrm{SD} ; n=30$ ) was added to each plate. Plots were fitted to a sigmoidal dose-response curve with GraphPad Prism software version 4.00 for Windows (San Diego CA, USA). The titer of the plasma was determined from the reciprocal of the dilution of the EC50 value. A titer of 10 was given to non-responders, and statistical analyses were performed with a Kruskal-Wallis non-parametric one-way ANOVA and Dunn's multiple comparison test.

\section{Neutralizing Antibody Assay}

A bioassay that was based on inhibition of induction of myxovirus resistance protein $\mathrm{A}(\mathrm{MxA})$ gene expression in an A549 cell line (26) was used to measure NAB levels at day 21 in plasma. MxA and a control housekeeping genederived mRNA (eukaryotic 18S rRNA) were detected with a real-time RT-PCR multiplex assay. Neutralizing activity was measured in ten-fold reduction units per $\mathrm{ml}(\mathrm{TRU} / \mathrm{ml})$. Plasma samples were considered NAB-negative if neutralizing activity was below $130 \mathrm{TRU} / \mathrm{ml}(10,26)$.

\section{RESULTS}

\section{Physicochemical Characteristics of rhIFN $\beta$ - Ia Structural Variants}

\section{Visual Inspection}

A homogeneous white haze was visible in all protein preparations with an intensity that was highest for metalcatalyzed oxidized and lowest for untreated $\operatorname{rhIFN} \beta-1 \mathrm{a}$, with the $\mathrm{H}_{2} \mathrm{O}_{2}$-treated product being slightly more turbid than the guanidine-treated product. No distinct visible particles could be discerned.

\section{Dynamic Light Scattering (DLS)}

The size distributions of the samples measured by dynamic light scattering (DLS) varied considerably between repeated runs; therefore, average diameters (Z-ave) and polydispersity indices (PDI) are presented (Table I). In line with previous results (10), untreated $\operatorname{rhIFN} \beta$-la showed high values for both Z-ave $(3.2 \mu \mathrm{m})$ and PDI (1.0), indicating the presence of large aggregates heterogeneous in size. The aggregates in untreated rhIFN $\beta$-1a disassembled upon addition of $0.01 \%(w / v)$ SDS, however, not completely given the observed Z-ave of $210 \mathrm{~nm}$ and the theoretical diameter of approximately $3 \mathrm{~nm}$ for monomeric rhIFN $\beta$ - la according to its crystal structure (6). $\mathrm{H}_{2} \mathrm{O}_{2}$-oxidized rhIFN $\beta$-1a had similar Z-ave and PDI as untreated rhIFN $\beta-1 \mathrm{a}$, both in absence and presence of SDS. The Zave of metal-catalyzed oxidized rhIFN $\beta$-1a in absence of SDS was slightly smaller and in presence of SDS slightly larger than those of untreated and $\mathrm{H}_{2} \mathrm{O}_{2}$-oxidized rhIFN $\beta$ 1a. This suggests that the aggregates in the metal-catalyzed oxidized preparation differed from those in the untreated product. Guanidine-treated $\operatorname{rhIFN} \beta-1$ a demonstrated a remarkably lower Z-ave and PDI than untreated rhIFN $\beta$ la (without SDS), which can be explained by dissociation of some of the aggregates upon unfolding with guanidine. The 
Table I Overview of the Physicochemical Characteristics of Untreated (Untreated), Metal-Catalyzed Oxidized (MCO), Hydrogen Peroxide Treated $\left(\mathrm{H}_{2} \mathrm{O}_{2}\right)$, and Guanidine Treated (Guanidine) rhIFN $\beta$ - la

${ }^{a} 0.01 \%(W / N)$ SDS was added to the rhIFN $\beta$ - I a preparations before analysis.

${ }^{b}$ Fractions were calculated from the area under the curve (AUC) for each peak and an extinction coefficient $\left(E_{0.1 \%}^{\mid c m}\right)$ rhIFNß- Ia at $\lambda=280 \mathrm{~nm}$ (32). The range of each fraction is shown in Fig. 2

c Percentages were based on the $A \cup C$ of each peak relative to the total AUC for untreated rhIFNß-Ia. The different RP-HPLC peaks are shown in Fig. 3

\begin{tabular}{llllll}
\hline Method & Parameter & Untreated & $\mathrm{MCO}$ & $\mathrm{H}_{2} \mathrm{O}_{2}$ & Guanidine \\
\hline DLS & Z-ave $(\mu \mathrm{m})$ & 3.2 & 1.6 & 3.9 & 0.35 \\
& Z-ave with SDS $(\mu \mathrm{m})$ & 0.21 & 0.54 & 0.12 & 0.14 \\
& PDI & 1.0 & 1.0 & 1.0 & 0.4 \\
& PDI with SDS & \\
& OD280/OD260 & 0.5 & 0.7 & 0.5 & 0.5 \\
& OD280/OD260 with SDS & & & \\
& OD350 nm & 1.03 & 0.99 & 0.95 & 0.94 \\
& OD350 nm with SDS & 1.58 & 1.02 & 1.89 & 1.85 \\
& Monomer fraction (\%) & 0.13 & 0.21 & 0.25 & 0.28 \\
HP-SEC & & 71 & 0.16 & -0.01 & -0.01 \\
& Dimer fraction (\%) & 14 & 13 & 61 & 18 \\
& Oligomer fraction (\%) & 2 & 8 & 10 & 42 \\
& Unrecovered fraction (\%) & 13 & 68 & 9 & 28 \\
RP-HPLC $^{c}$ & "Native" fraction (\%) & 94 & 11 & 20 & 12 \\
& Oxidized fraction (\%) & 0 & 2 & 0 & 7 \\
& Aggregated fraction (\%) & 6 & 0 & 63 & 0 \\
& Unrecovered fraction (\%) & 0 & 0 & 0 & 62 \\
& & 98 & 37 & 31 \\
\hline
\end{tabular}

decrease in Z-ave after the addition of SDS indicates that part of the (larger) aggregates in the guanidine-treated preparation was non-covalently bound.

\section{Zero-Order UV Spectroscopy}

In addition to the absorbance around $280 \mathrm{~nm}$ caused by aromatic amino acid residues and disulfide bonds, the zeroorder UV spectra of proteins can show wavelengthdependent apparent absorbance due to aggregates in the solution that scatter light (23). The light scattering intensity depends on aggregate size, shape, and amount, and is more pronounced at lower wavelengths. A decrease in optical density (OD) at $350 \mathrm{~nm}$ in untreated rhIFN $\beta$-1a from 0.13 to 0.01 after addition of $0.01 \%(w / v)$ SDS indicates the presence of non-covalently bound aggregates (Table I). In absence of SDS, metal-catalyzed oxidized and $\mathrm{H}_{2} \mathrm{O}_{2}$ - and guanidine-treated rhIFN $\beta$-la showed decreased OD280/ OD260 ratios and increased OD350 values as compared with untreated $\mathrm{rhIFN} \beta$-la, indicating extensive aggregation (Fig. 1a). The UV spectrum of metal-catalyzed oxidized rhIFN $\beta$ - la was least affected by the addition of SDS, indicating the presence of a significant amount of covalent aggregates in this preparation (Fig. 1c).

\section{Second-Derivative UV Spectroscopy}

Second-derivative UV spectra of proteins provide valuable information on chromophores distributed throughout the protein molecule and are sensitive to a wide variety of chemical and structural changes $(23,24)$. Peaks in the wavelength region between 240 and $270 \mathrm{~nm}$ can be attributed mainly to phenylalanine, while tyrosine and tryptophan are responsible for peaks between 275 and $310 \mathrm{~nm}$, with the region between 295 and $310 \mathrm{~nm}$ being affected mostly by tryptophan (24). Without SDS, the second-derivative UV spectra of the degraded samples clearly differed from that of untreated rhIFN $\beta$-1a, particularly in the Tyr and Trp region (Fig. 1b). The microenvironment of the phenylalanines in guanidine-treated rhIFN $\beta$-1a also differed from that in untreated rhIFN $\beta$ la. The complete spectrum of guanidine-treated $\operatorname{rhIFN} \beta$-la showed a red shift of 0.5-0.7 $\mathrm{nm}$ as compared with untreated rhIFN $\beta$-la, indicating a more hydrophobic environment of the chromophores (23). The addition of $0.01 \%(w / v)$ SDS resulted in nearly overlaying secondderivative $\mathrm{UV}$ spectra of untreated and $\mathrm{H}_{2} \mathrm{O}_{2}{ }^{-}$and guanidine-treated rhIFN $\beta$-1a (Fig. 1d). Interestingly, the second-derivative UV spectrum of metal-catalyzed oxidized rhIFN $\beta$-1a was hardly affected by the addition of SDS and differed considerably from the other spectra in all regions (Fig. 1d). In particular, the intensities of the positive and negative peaks in the spectrum are relatively low, suggesting that the aromatic amino acid residues in metal-catalyzed rhIFN $\beta$ - 1 a remained buried in presence of SDS.

\section{High Performance Size Exclusion Chromatography (HP-SEC)}

The elution buffer used for high performance size exclusion chromatography (HP-SEG) contained $0.1 \%(w / v)$ SDS to reduce the interaction of the protein with the column material (27). Since SDS may dissociate non-covalent protein bonds, this HP-SEC method allows us to detect monomers and covalently bound or strongly associated 

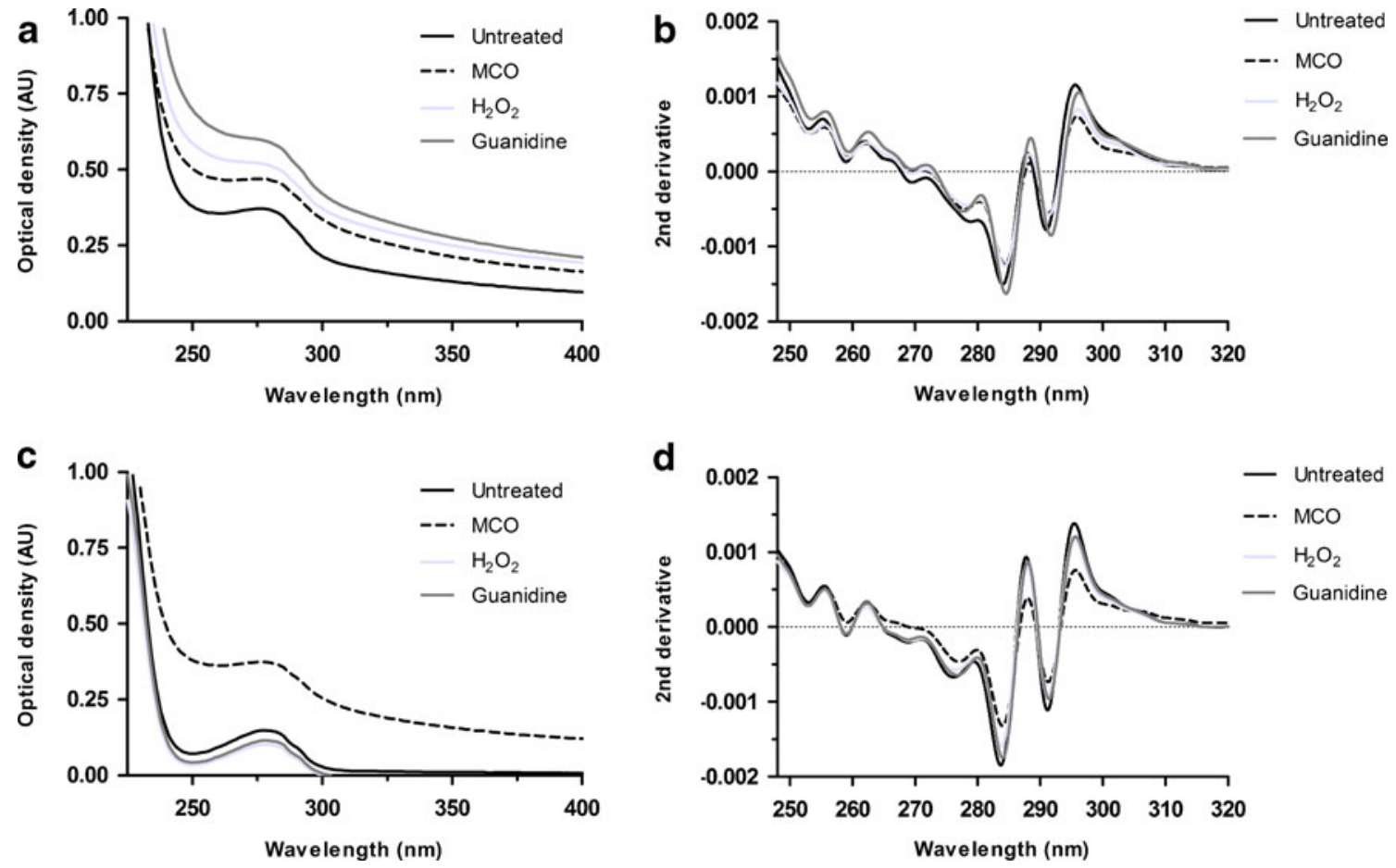

Fig. I UV spectra $(\mathbf{a}, \mathbf{c})$ and second-derivative UV spectra $(\mathbf{b}, \mathbf{d})$ in the absence $(\mathbf{a}, \mathbf{b})$ and presence $(\mathbf{c}, \mathbf{d})$ of $0.01 \%(w / V)$ SDS, of untreated (Untreated), metal-catalyzed-oxidized (MCO), hydrogen peroxide-treated $\left(\mathrm{H}_{2} \mathrm{O}_{2}\right)$, and guanidine-treated (Guanidine) rhIFN $\beta$ - Ia.

non-covalent multimers of rhIFN $\beta$-la (Fig. 2 and Table I). The chromatograms generally showed three different peaks, which could be attributed to rhIFN $\beta$-la monomers, dimers, and oligomers according to previous observations (10). The oligomers eluted after the void volume but before the dimers, thus possessing molecular weights between $45 \mathrm{kDa}$ and $150 \mathrm{kDa}$, which is the column exclusion limit. The monomer peaks were slightly tailing, probably due to partial unfolding of the rhIFN $\beta$-1a monomer and/or interaction with the column material. All preparations showed an unrecovered fraction (Table I), which may be due to aggregates too large to enter the column or unfolded proteins adsorbing onto the column material. Untreated rhIFN $\beta$-la contained mainly monomeric protein $(71 \%)$, whereas most metal-catalyzed oxidized rhIFN $\beta$ - 1 a eluted as oligomer $(68 \%) . \mathrm{H}_{2} \mathrm{O}_{2}$-mediated oxidation of $\operatorname{rhIFN} \beta$-la resulted in increased percentages of oligomer $(7 \%)$ and unrecovered protein $(20 \%)$ as compared with untreated $\operatorname{rhIFN} \beta-1 \mathrm{a}(2 \%$ and $13 \%$, respectively). Guanidine-treated $\operatorname{rhIFN} \beta-1 \mathrm{a}$, on the other hand, showed relatively high percentages of dimer $(42 \%)$ and oligomer $(28 \%)$.

\section{Reversed-Phase High Performance Liquid Chromatography (RP-HPLC)}

During RP-HPLC of rhIFN $\beta$-la an oxidized form of the protein (presumably a methionine sulfoxide derivative) has been reported to elute prior to the main peak, followed by several other peaks containing oligomerized protein (25). When applying the same method, untreated rhIFN $\beta$-la was found to consist of "native" protein and a relatively low percentage $(6 \%)$ of aggregates without any detectable oxidation (Fig. 3 and Table I). Metal-catalyzed oxidized rhIFN $\beta$-la showed a very low protein recovery of $2 \%$ compared with untreated rhIFN $\beta$-la, likely because a high amount of aggregates was captured by the guard column. About $63 \%$ of $\mathrm{H}_{2} \mathrm{O}_{2}$-treated rhIFN $\beta$-la eluted at a position corresponding to oxidized $\operatorname{rhIFN} \beta-1 \mathrm{a}$, while the remaining protein fraction was not recovered. The guanidine-treated preparation contained some native rhIFN $\beta-1 \mathrm{a}(7 \%)$ and large fractions of detectable $(62 \%)$ as well as non-detectable $(31 \%)$ aggregates, but no measurable amounts of oxidized protein.

\section{Immunogenicity}

The total anti-rhIFN $\beta$ IgG titers after 3 weeks of injections with untreated and degraded rhIFN $\beta$-1a in wild-type mice are shown in Fig. 4a. All samples induced antibodies, which was expected since human interferon beta is a foreign protein to wild-type mice (10-12). The antibodies were measured against untreated $\operatorname{rhIFN} \beta-1 \mathrm{a}$. In addition to binding antibodies (BABs), the majority of the wild-type mice showed neutralizing antibodies (NABs) against all products (Table II). These results imply that all preparations contained preserved epitopes present in native rhIFN $\beta$-1a. Figure $4 \mathrm{~b}$ shows the $\operatorname{IgG}$ response of the 

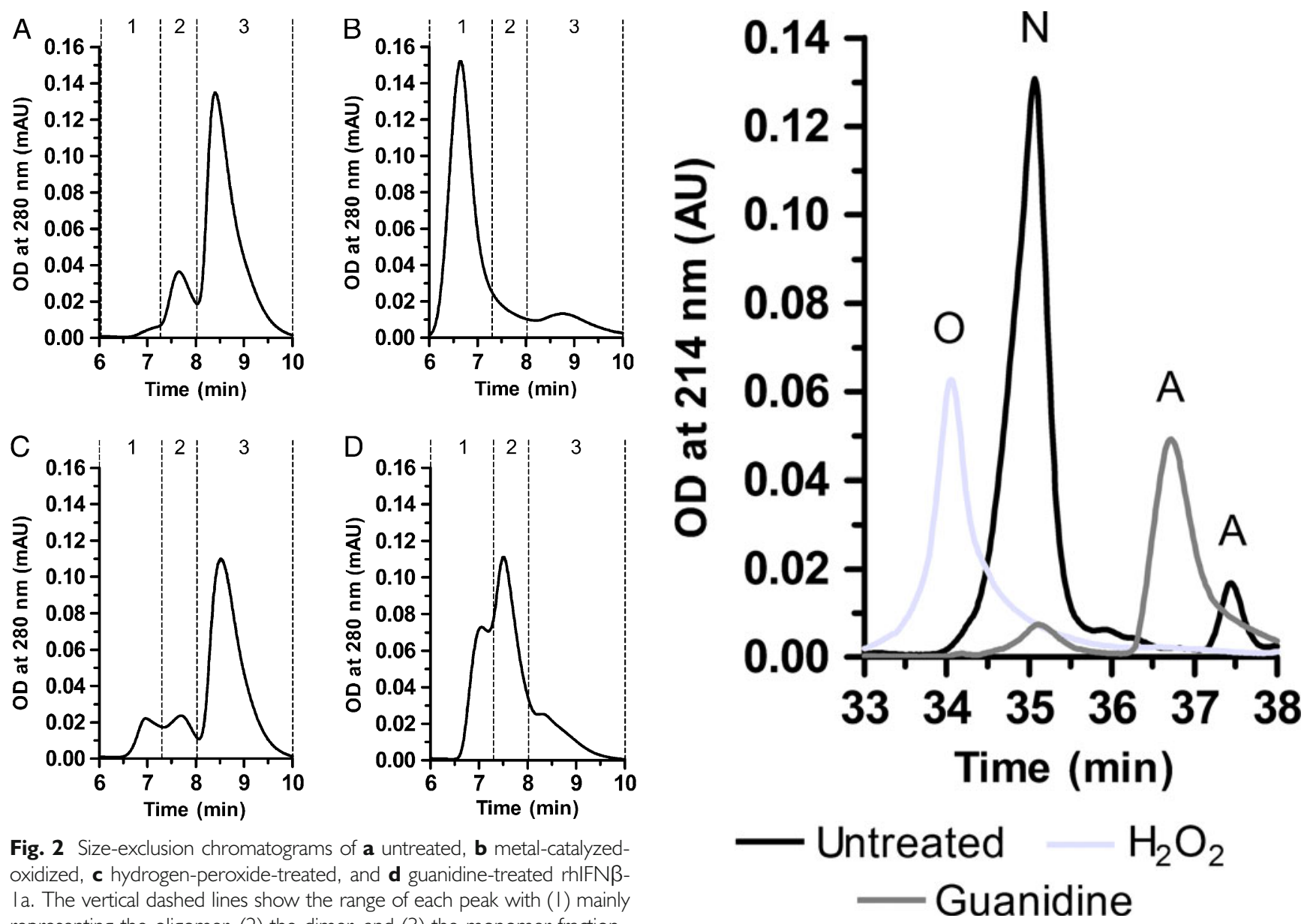

Fig. 2 Size-exclusion chromatograms of $\mathbf{a}$ untreated, $\mathbf{b}$ metal-catalyzedoxidized, $\mathbf{c}$ hydrogen-peroxide-treated, and $\mathbf{d}$ guanidine-treated rhIFN $\beta$ Ia. The vertical dashed lines show the range of each peak with (I) mainly representing the oligomer, (2) the dimer, and (3) the monomer fraction.

transgenic mice against the different $\operatorname{rhIFN} \beta$-la preparations. The transgenic mice were immune-tolerant for untreated rhIFN $\beta$-la except for two animals. Similar low immunogenicity in transgenic mice was observed for guanidine-treated rhIFN $\beta-1$. Metal-catalyzed oxidized $\operatorname{rhIFN} \beta-1$ a, however, was significantly more immunogenic than the untreated product, with $100 \%$ of the mice responding. Also, $\mathrm{H}_{2} \mathrm{O}_{2}$-mediated oxidation seemed to increase the immunogenicity of untreated rhIFN $\beta-1 \mathrm{a}$, with eight out of nine mice responding. Hardly any transgenic mice showed NABs at day 21 (Table II), in concordance with previous observations $(10,12)$.

\section{DISCUSSION}

The unwanted immunogenicity of therapeutic cytokines, like that of other protein pharmaceuticals, is greatly influenced by the molecular characteristics $(10,20)$. To investigate the effect of oxidation and aggregation on the immunogenicity of interferon beta, four different rhIFN $\beta$ la samples were prepared, characterized, and tested in transgenic immune-tolerant mice.

Fig. 3 RP-HPLC analysis of untreated (Untreated), hydrogen-peroxidetreated $\left(\mathrm{H}_{2} \mathrm{O}_{2}\right)$ and guanidine-treated (Guanidine) rhIFN $\beta$-Ia. The chromatogram of metal-catalyzed-oxidized rhIFNß-la was not included because hardly any peaks were detected. Peaks are labeled with $(O)$ representing oxidized, $(N)$ "native," and $(A)$ aggregated rhIFN $\beta$ - Ia.

The starting material, untreated $\operatorname{rhIFN} \beta-1 \mathrm{a}$, contained about $70 \%$ monomer as well as dimer, oligomer, and most likely protein that was too large to be recovered by HP-SEC. Some large non-covalent aggregates were present, measuring up to $3 \mu \mathrm{m}$ and heterogeneous in size according to DLS. Almost $80 \%$ of the metal-catalyzed oxidized rhIFN $\beta$-1a product consisted of oligomers and larger aggregates with a relatively high degree of covalent bonds. $\mathrm{H}_{2} \mathrm{O}_{2}$-treated rhIFN $\beta$-1a showed similar diameter and polydispersity in absence and presence of SDS as untreated rhIFN $\beta$-1a, but it contained about 10\% less monomer according to HPSEC. Guanidine-treated rhIFN $\beta$-1a mostly consisted of dimers and oligomers, in total comprising $70 \%$ of the sample according to HP-SEG. The larger aggregates detected by DLS were less heterogeneous and smaller in size (up to $0.4 \mu \mathrm{m}$ ) than those in untreated rhIFN $\beta$-1a.

Second-derivative UV spectroscopy demonstrated changes in the tertiary protein structure of the degraded samples compared to the untreated product. The chromophores in 

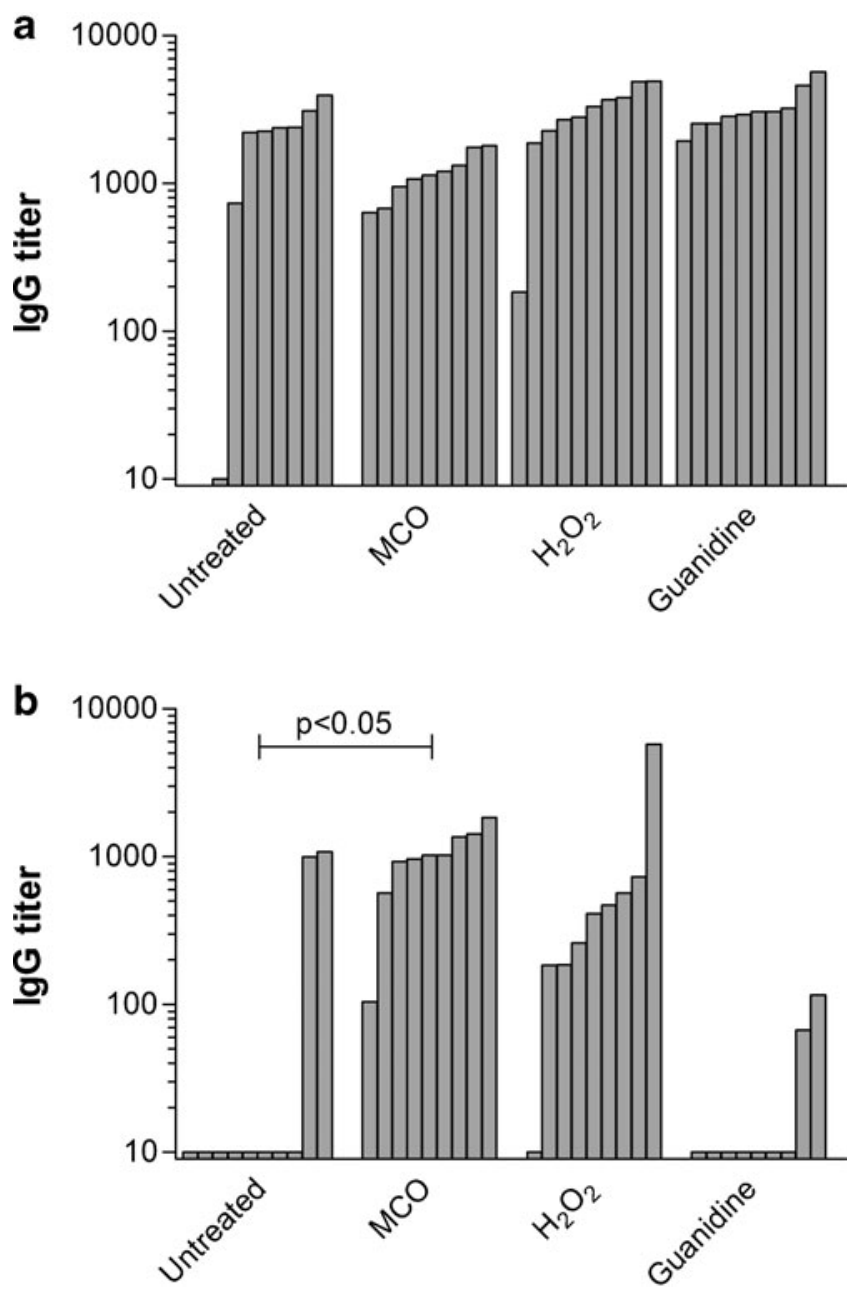

Fig. 4 Immunogenicity of untreated, metal-catalyzed-oxidized (MCO), hydrogen-peroxide-treated $\left(\mathrm{H}_{2} \mathrm{O}_{2}\right)$ and guanidine-treated (Guanidine) rhIFN $\beta$ - I a in (a) wild-type and (b) transgenic mice. Bars show BAB titers of total IgG against rhIFN $\beta$ as determined by ELISA at day 21 for each individual mouse injected daily, from Monday to Friday, i.p. for 3 weeks. Non-responders were given a titer of 10 . Statistical analyses (Kruskal-Wallis non-parametric one-way ANOVA with Dunn's multiple comparison test) were performed comparing the titers of each treatment group with the titers of mice injected with untreated rhIFN $\beta$ - Ia. Treatment groups that differ significantly $(p<0.05)$ from the mice injected with untreated rhIFN $\beta$ la are indicated.

guanidine-treated rhIFN $\beta$-la showed shifts to more hydrophobic environments, possibly due to the degradation procedure involving denaturation and subsequent refolding of slightly unfolded proteins in the untreated product. Also, the formation of additional dimers and oligomers could have reduced the exposure of these residues to the solution. In presence of SDS, the second-derivative UV spectrum of metal-catalyzed oxidized rhIFN $\beta$-1a showed remarkable differences with the other samples, suggesting a high proportion of covalent aggregates and/or chemically modified (perhaps oxidized) chromophores.

Protein oxidation was detected in $\mathrm{H}_{2} \mathrm{O}_{2}$-treated rhIFN $\beta$-1a but not in untreated or guanidine-treated
Table II Number of Wild-Type and Transgenic Mice Out of the Total Number of Mice Per Treatment Group Showing Neutralizing Antibodies Against rhIFN $\beta$ at Day 21. Six Out of 80 Mice Died During the Study Due to Handling or Other Reasons, Such as Liver or Heart Problems

\begin{tabular}{|c|c|c|}
\hline & Wildtype & Transgenic \\
\hline Untreated rhIFN $\beta$ - Ia & $7 / 8$ & $0 / 10$ \\
\hline Metal-catalyzed-oxidized rhIFNß-Ia & $6 / 9$ & $0 / 9$ \\
\hline $\mathrm{H}_{2} \mathrm{O}_{2}$-treated rhIFNß-la & $9 / 10$ & $1 / 9$ \\
\hline Guanidine-treated rhIFN $\beta$ - Ia & $9 / 10$ & $0 / 9$ \\
\hline
\end{tabular}

rhIFN $\beta-1$ a. Theoretically, it is possible that the unrecovered fraction $(31 \%)$ in RP-HPLC of guanidine-treated rhIFN $\beta$-1a (Table I) contained oxidized protein. However, it is not likely that incubation with guanidine would cause protein oxidation. Oxidation of the highly aggregated metal-catalyzed oxidized rhIFN $\beta$-1a could not be assessed with RP-HPLC using UV detection, due to low protein recovery. For this reason, preliminary tests were performed with liquid chromatography mass spectrometry (LC-MS), demonstrating that metal-catalyzed oxidation of rhIFN $\beta$-1a increased the ratio of oxidized versus nonoxidized Trp22 two-fold compared with untreated rhIFN $\beta$-1a (data not shown). Oxidation apparently affected the tryptophan at position 22 , which is close to the receptor binding site and relatively exposed to the solvent $(7,28)$. We also have indications based on intrinsic fluorescence (excited at $360 \mathrm{~nm}$ ) and 4-(aminomethyl)-benzenesulfonic acid derivative fluorescence that the metal-catalyzed oxidized sample contained relatively high amounts of oxidized aromatic residues. Interestingly, metal-catalyzed oxidized rhIFN $\beta$-la was significantly more immunogenic than untreated rhIFN $\beta$-1a in transgenic mice immune tolerant for human interferon beta. $\mathrm{H}_{2} \mathrm{O}_{2}$-oxidized rhIFN $\beta-1 \mathrm{a}$ induced $\mathrm{BABs}$ in a high percentage of transgenic mice $(88 \%)$ compared with untreated and guanidine-treated rhIFN $\beta-1$ a $(20 \%$ and $22 \%$, respectively); however, the difference in BAB levels between these samples was not statistically significant. Although guanidine-treated rhIFN $\beta$ - la was considerably aggregated, it showed poor immunogenicity comparable to untreated rhIFN $\beta-1 \mathrm{a}$ in transgenic mice.

The multiple processes involved, such as aggregation, oxidation, and change in conformation, make it difficult to determine the contribution of each to the observed immunogenicity. Yet we hypothesize that a particular combination of oxidation and aggregation could be responsible for the immune response against rhIFN $\beta$-1a. Likewise, oxidized and aggregated recombinant human interferon alpha-2b (rhIFN $\alpha-2 b)$ induced antibodies in transgenic immune-tolerant mice, whereas protein that was either oxidized or aggregated did not trigger an 
immune response in these mice (20). Metal-catalyzed oxidation of rhIFN $\alpha-2 b$ was reported to result in the formation of methionine sulfoxides as well as covalent aggregates. Hermeling et al. proposed that these aggregates comprised repetitive (more than 10), optimally spaced (5$10 \mathrm{~nm}$ ), and native-like epitopes that could stimulate B-cells to produce antibodies (29-31) and thereby break immune tolerance of the transgenic mice. $\mathrm{H}_{2} \mathrm{O}_{2}$-treated rhIFN $\alpha$-2b also contained oxidized methionines but no detectable aggregates, explaining the absence of antibodies against this product in transgenic mice (20). In the present study, aggregates were formed by $\mathrm{H}_{2} \mathrm{O}_{2}$-mediated oxidation of $\operatorname{rhIFN} \beta-1 \mathrm{a}$, which is a protein with relatively poor solubility and a high propensity to aggregate (6-8), as compared to rhIFN $\alpha-2 b$.

The tolerance of transgenic mice for glutaraldehyde-treated and boiled rhIFN $\alpha-2 \mathrm{~b}$ was explained by the loss of native epitopes according to the absence of anti-rhIFN $\alpha-2 b$ IgG titers in wild-type mice (20). In our study, loss of native epitopes was most probably not the reason for the poor immunogenicity of untreated and guanidine-treated $\operatorname{rhIFN} \beta-1 \mathrm{a}$, since the wildtype mice developed anti-rhIFN $\beta-1 \mathrm{a}$ IgG and NABs. Apparently, aggregation without oxidation is not sufficient to trigger a robust immune response against rhIFN $\beta$-1a in our transgenic mouse model, as was seen for untreated and guanidine-treated rhIFN $\beta$-1a as well as previously studied stressed rhIFN $\beta$-1a (10). Oxidation of an amino acid residue may lead to alterations in secondary and tertiary protein structure, enhance the exposure of hydrophobic areas and consequently result in protein aggregation (19). In general, $\mathrm{H}_{2} \mathrm{O}_{2}$ or other oxidizing agents in solution induce chemical modifications of the more solvent-exposed labile amino acid residues, whereas trace metal ions rather cause modification of amino acid residues in the vicinity of metal-binding sites, such as the ionic side chains of asparagine, glutamine, and lysine (19). Different mechanisms of oxidation and subsequent aggregation account for differences in the characteristics of the aggregates, such as size, covalent versus non-covalent bonds, and degree of conformational change. Further research is definitely needed to elucidate how oxidative pathways lead to aggregation and how this relates to the risk of (enhanced) immunogenicity. Strategies to prevent oxidation (e.g. by adding antioxidants or chelating agents) during processing and formulation of pharmaceutical proteins must be based on the underlying mechanism leading to protein modification.

\section{CONCLUSIONS}

This work shows that oxidation of $\operatorname{rhIFN} \beta$-1a via two different pathways led to aggregation of the protein, thereby increasing the risk of immunogenicity as demon- strated in our transgenic immune-tolerant mouse model. In contrast, two different products that were highly aggregated but did not contain measurable levels of oxidation were hardly immunogenic in the same mouse model. Especially metal-catalyzed oxidation of rhIFN $\beta$-1a may lead to the formation of aggregates with distinct characteristics capable of overcoming the immune tolerance for the protein.

\section{ACKNOWLEDGMENTS}

This research was financially supported by the European Community under its 6th Framework (project NABINMS, contract number 018926). Biogen Idec Inc. is acknowledged for kindly providing test products. We thank Susan Goelz for her valuable suggestions. Christian Schöneich and Victor S. Sharov (Department of Pharmaceutical Chemistry, University of Kansas) are acknowledged for providing support with LC-MS.

Open Access This article is distributed under the terms of the Creative Commons Attribution Noncommercial License which permits any noncommercial use, distribution, and reproduction in any medium, provided the original author(s) and source are credited.

\section{REFERENCES}

1. Schellekens H. Immunogenicity of therapeutic proteins: clinical implications and future prospects. Clin Ther. 2002;24:1720-40.

2. Sorensen PS. Review: neutralizing antibodies against interferonbeta. Ther Adv Neurol Disord. 2008;1:125-41.

3. Rosenberg AS. Effects of protein aggregates: an immunologic perspective. AAPS J. 2006;8:E501-7.

4. Schellekens H. Bioequivalence and the immunogenicity of biopharmaceuticals. Nat Rev Drug Discov. 2002;1:457-62.

5. Baker DP, Pepinsky RB, Brickelmaier M, Gronke RS, Hu X, Olivier K, et al. PEGylated interferon beta-la: meeting an unmet medical need in the treatment of relapsing multiple sclerosis. J Interferon Cytokine Res. 2010;30:777-85.

6. Karpusas M, Nolte M, Benton CB, Meier W, Lipscomb WN, Goelz S. The crystal structure of human interferon-beta at 2.2- $\AA$ resolution. Proc Natl Acad Sci USA. 1997;94:11813-8.

7. Karpusas M, Whitty A, Runkel L, Hochman P. The structure of human interferon-beta: implications for activity. Cell Mol Life Sci. 1998;54:1203-16.

8. Runkel L, Meier W, Pepinsky RB, Karpusas M, Whitty A, Kimball K, et al. Structural and functional differences between glycosylated and non-glycosylated forms of human interferon-beta (IFN-beta). Pharm Res. 1998;15:641-9.

9. van Beers MMC, Jiskoot W, Schellekens H. On the role of aggregates in the immunogenicity of recombinant human interferon beta in patients with multiple sclerosis. J Interferon Cytokine Res. 2010;30:767-75.

10. van Beers MMC, Sauerborn M, Gilli F, Brinks V, Schellekens H, Jiskoot W. Aggregated recombinant human interferon beta induces antibodies but no memory in immune-tolerant transgenic mice. Pharm Res. 2010;27:1812-24.

11. Hermeling S, Jiskoot W, Crommelin DJA, Bornæs C, Schellekens H. Development of a transgenic mouse model immune tolerant for human interferon beta. Pharm Res. 2005;22:847-51. 
12. van Beers MMC, Sauerborn M, Gilli F, Hermeling S, Schellekens $\mathrm{H}$, Jiskoot W. Hybrid transgenic immune tolerant mouse model for assessing the breaking of $\mathrm{B}$ cell tolerance by human interferon beta. J Immunol Methods. 2010;352:32-7.

13. Hermeling S, Crommelin D, Schellekens H, Jiskoot W. Structureimmunogenicity relationships of therapeutic proteins. Pharm Res. 2004;21:897-903.

14. Sharma B. Immunogenicity of therapeutic proteins. Part 1: impact of product handling. Biotechnol Adv. 2007;25:310-7.

15. Patro SY, Freund E, Chang BS. Protein formulation and fill-finish operations. Biotechnol Annu Rev. 2002;8:55-84.

16. Shacter E. Quantification and significance of protein oxidation in biological samples. Drug Metab Rev. 2000;32:307-26.

17. Lam XM, Yang JY, Cleland JL. Antioxidants for prevention of methionine oxidation in recombinant monoclonal antibody HER2. J Pharm Sci. 1997;86:1250-5.

18. Roy S, Mason BD, Schöneich CS, Carpenter JF, Boone TC, Kerwin BA. Light-induced aggregation of type I soluble tumor necrosis factor receptor. J Pharm Sci. 2009;98:3182-99.

19. Li S, Nguyen TH, Schöneich C, Borchardt RT. Aggregation and precipitation of human relaxin induced by metal-catalyzed oxidation. Biochemistry. 1995;34:5762-72.

20. Hermeling S, Aranha L, Damen JMA, Slijper M, Schellekens H, Crommelin DJA, et al. Structural characterization and immunogenicity in wild-type and immune tolerant mice of degraded recombinant human interferon alpha2b. Pharm Res. 2005;22:1997-2006.

21. Schöneich C. Mechanisms of protein damage induced by cysteine thiyl radical formation. Chem Res Toxicol. 2008;21:1175-9.

22. Interferon alpha2b. European Pharmacopeia 50. Vol.2:18121815 (2004)

23. Kueltzo LA, Middaugh CR. Ultraviolet absorption spectroscopy. In: Jiskoot W, Crommelin DJA, editors. Methods for structural analysis of protein pharmaceuticals, vol. III. Arlington: AAPS Press; 2005. p. 1-25.

24. Levine RL, Federici MM. Quantitation of aromatic residues in proteins: model compounds for second-derivative spectroscopy. Biochemistry. 1982;21:2600-6.

25. Geigert J, Panschar BM, Fong S, Huston HN, Wong DE, Wong DY, et al. The long-term stability of recombinant (serine-17) human interferon- $\beta$. J Interferon Res. 1988;8:539-47.

26. Gilli F, van Beers M, Marnetto F, Jiskoot W, Bertolotto A, Schellekens H. Development of a bioassay for quantification of neutralising antibodies against human interferon-beta in mouse sera. J Immunol Methods. 2008;336:119-26.

27. Hawe A, Friess W. Development of HSA-free formulations for a hydrophobic cytokine with improved stability. Eur J Pharm Biopharm. 2008;68:169-82.

28. Runkel L, deDios C, Karpusas M, Betzenhauser M, Muldowney C, Zafari M, et al. Systematic mutational mapping of sites on human interferon-beta-la that are important for receptor binding and functional activity. Biochemistry. 2000;39:2538-51.

29. Bachmann MF, Rohrer UH, Kundig TM, Burki K, Hengartner $\mathrm{H}$, Zinkernagel RM. The influence of antigen organization on B cell responsiveness. Science. 1993;262:1448-51.

30. Chackerian B, Lenz P, Lowy DR, Schiller JT. Determinants of autoantibody induction by conjugated papillomavirus virus-like particles. J Immunol. 2002;169:6120-6.

31. Dintzis RZ, Okajima M, Middleton MH, Greene G, Dintzis HM. The immunogenicity of soluble haptenated polymers is determined by molecular mass and hapten valence. J Immunol. 1989;143:1239-44.

32. Gill SC, von Hippel PH. Calculation of protein extinction coefficients from amino acid sequence data. Anal Biochem. 1989;182:319-26. 